

\section{DISCLAIMER}

This report was prepared as an account of work sponsored by an agency of the United States Government. Neither the United States Government nor any agency Thereof, nor any of their employees, makes any warranty, express or implied, or assumes any legal liability or responsibility for the accuracy, completeness, or usefulness of any information, apparatus, product, or process disclosed, or represents that its use would not infringe privately owned rights. Reference herein to any specific commercial product, process, or service by trade name, trademark, manufacturer, or otherwise does not necessarily constitute or imply its endorsement, recommendation, or favoring by the United States Government or any agency thereof. The views and opinions of authors expressed herein do not necessarily state or reflect those of the United States Government or any agency thereof. 


\section{DISCLAIMER}

Portions of this document may be illegible in electronic image products. Images are produced from the best available original document. 


\footnotetext{
This report was prepared as an account of Government sponsored work. Neither the United States, nor the Commission, nor any person acting on behalf of the Commission:

A. Makes any warranty or representation, expressed or implied, with respect to the accuracy, completeness, or usefulness of the information contained in this report, or that the use of any information, apparatus, method, or process disclosed in this report may not infringe privately owned rights; or

B. Assumes any liabilities with respect to the use of, or for damages resulting from the use of any information, apparatus, method, or process disclosed in this report.

As used in the above, "person acting on behalf of the Commission" includes any employee or contractor of the Commission, or employee of such contractor, to the extent that such employee or contractor of the Commission, or employee of such contractor prepares, disseminates, or provides access to, any information pursuant to his employment or contract with the Commission, or his employment with such contractor.
}

Printed in the United States of America

Available from

Clearinghouse for Federal Scientific and Technical Information

National Bureau of Standards, U. S. Department of Commerce

Springfield, Virginia 22151

Price: Printed Copy $\$ 3.00$; Microfiche $\$ 0.65$ 


\title{
A PHYSICAL INVENTORY OF THE ENRICHED URANIUM IN A SOLUTION SYSTEM
}

\author{
Robert E. Rothe
}

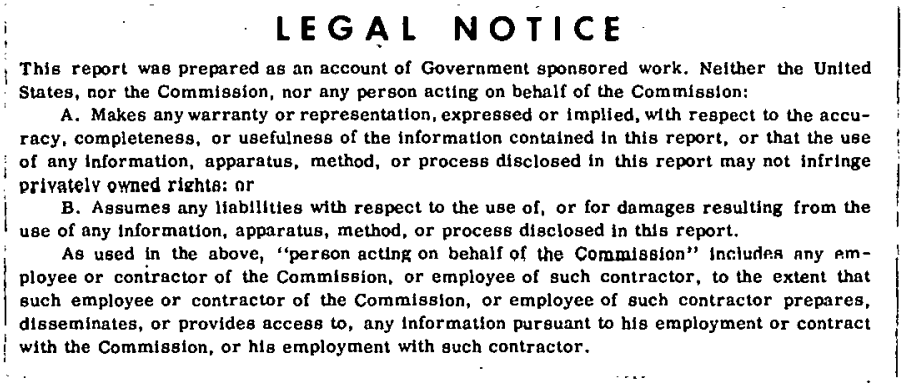
THE DOW CHEMICAL COMPANY ROCKY FLATS DIVISION
P. O. BOX 888
GOLDEN, COLORADO 80401
U. S. ATOMIC ENERGY COMMISSION CONTRACT AT(29:1)-1106




\section{CONTENTS}

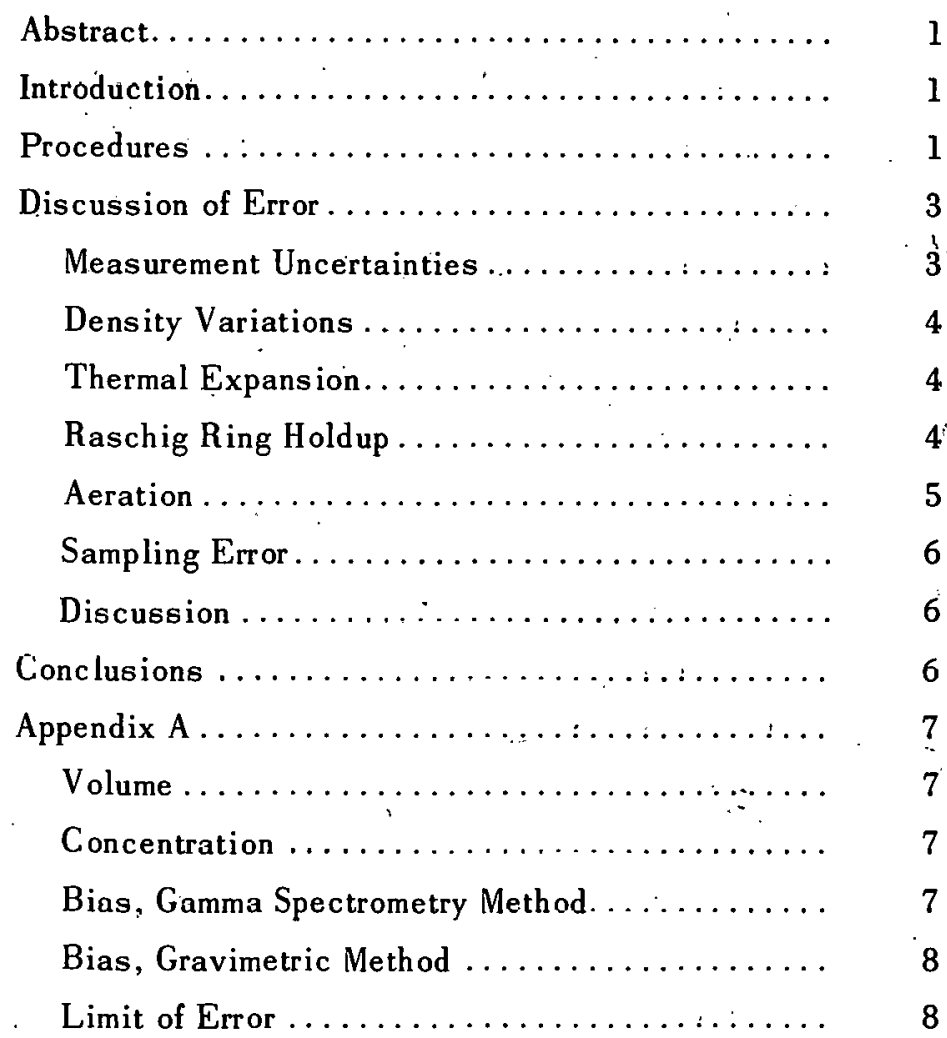




\title{
A PHYSICAL INVENTORY OF THE ENRICHED URANIUM IN A SOLUTION SYSTEM
}

\author{
Robert E. Rothe
}

\begin{abstract}
A high precision inventory of enriched uranium in solution form is reported, as well as techniques which contribute to the precision. Both statistical uncertainties due to measurements und imponderable sources of errors are discussed. Based on an evaluation of these uncertainties, the expected variation between successive future inventory measurements will lie between 1 and 2 percent.
\end{abstract}

\section{INTRODUCTION}

A high precision inventory of enriched uranium in solution form was measured. The inventory amounts to 561,280 grams. The solution is normally used in criticality measurements. The solution system is atypical of process systems for two reasons. No connections exist between the system and any other Material Balance Area. Serondly, the expcrimental program does not call for frequent changes in the fissile material inventory. These conditions allow convenient study of inventory control procedures. Furthermore, the system is large enough to allow accurate measurements. The capacity of the 10 storage tanks is 3,600 liters. The inventory gram weight of the enriched uranium is contained in about 2,500 liters of solution.

Considerable effort was spent evaluating the precision of the inventory. Two types of uncertainties were evaluated. The first type is the measurement uncertainty in the determination of the uranium concentration and in the volume of each solution variety. These values were calculated by Yvonne M. Ferris and are included in Appendix A, Page 7. The net uncertainty in the inventory at the 95 percent confidence level, due to measurement uncertainties, was slightly less than \pm 4 kilograms $(\mathrm{kg})$.

The second type of uncertainty is the imponderable crror wliuse effects were difficult to evaluate. Five such sources of error are discussed. The net expected difference between successive future inventories, including the measurement uncertainty, is expected to range bctween 5 and $10 \mathrm{~kg}$. These numbers correspond to 1 and 2 percent, respectively.

This report weighs the accuracy to which an inventory is made against the length of time required to achieve that accuracy. The length of an inventory should be minimized in order to reduce the time during which the uranium is unavailable for experimental use.

\section{PROCEDURES}

The inventory of the enriched uranium in the solution system of Building 886 is obtained by summing the inventories in each of several different solution types plus amounts in recoverable waste containers awaiting shipment. The inventory was begun on October 1,1968 and completed on January 31,1969 . Table I lists the materials, locations, and containers.

The material in Forms 1 through 6 contains solutions used in experiments. The small amount in Form 6 (salvage from inventory samples sent to the Analytical Laboratory) will be added to the solution of either Forms 2 or 3 . The solution in Form 7 contains undesirably high levels of impurity elements. This liquid was generated during the cleanup following the leak discovered November 30, 1967. It may be kept for experimental use to determine the effects of impurities. If not, the liquid will be concentrated (to reduce volume) and discarded or the uranium recovered in accord with the Atomic Energy Commission procedures. The material in Forms 8 and 9 was generated during the cleanup following the February 16, 1968 leak. The material was shipped to Oak Ridge, Tennessee, for recovery during February 1969.

The uranium content in Forms 1 through 5 and Form 7 was determined by multiplying measured volumes by measured uranium concentrations. The uranium content of Form 6 was determined by the Analytical Laboratory prior to shipment to Building 886 . The uranium content of $F$ orms 8 and 9 is the same amount as previously reported in an internal memorandum relating to the February 16, 1968 leak.

Table II gives the uranium inventory for each form, together with the measurement uncertainty expressed at the 95 percent confidence level. The entries in the concentration and volume columns have been rounded to ignore insignificant figures. The entries in the uranium-weight column, however, are derived from the unrounded numbers; they are not exactly 
TABLE I. Enriched Uranium Distribution.

\begin{tabular}{c} 
Form \\
\hline 1 \\
2 \\
3 \\
4 \\
5 \\
6 \\
7 \\
8 \\
9
\end{tabular}

\begin{tabular}{l} 
Material Description \\
\hline High Concentration Solution \\
Medium Concentration Solution \\
Medium Concentration Solution \\
Low Concentration Solution \\
Low Concentration Solution \\
Returned Samples \\
Impure Solution \\
Liquid Waste Solution \\
Paper Waste Material
\end{tabular}

Room
103
101
103
103
103
102
103
102
102

Containers

Tanks 443,444 , and 445

Tank 541

Tanks 441 and 44 ?

Tank 446

Tank 442

4 bottles

Unnumbered tank

16 containers

I 30-gallon drum derivable from the first two columns of Table II. The uncertainty calculations were performed by Yvonne $M$. Ferris and are discussèd In Appendix. A, Päge 7.

The last previous physical inventory was reported March 31,1967 . Its value was 560,636 grams, after adjusting for measured removals and additions to January 31,1969 . This inventory is 644 grams smaller than the inventory of Table II; the difference is about 0.1 percent and well within the expected uncertainty.

The isotopic content of the uranium was measured by the Mass Spectrographic Laboratory. Based on 26 determinations, Table III presents the average weight percent for the uranium isotopes. The uncertainties are again expressed at the 95 percent confidence level.

The measured concentrations reported in Table II are average values from the Analytical Laboratory. Altogether, Nuclear Safety submitted 34 samples for analysis in relation to this inventory. The average values have been corrected for a measured bias, determined from a Measurement Control Program specifically initiated to support this inventory. The Chemical Standards Group prepared 75 samples (having known concentrations between 1.05 and 483.8 grams per liter) which were analyzed by the Analytical Laboratory. The bias and its standard deviation were obtained from the data for both the gamma spectrometry (below 100 grams per liter) and the gravimetric (above 100 grams per liter) methods.

For the gamma spectrometry method (see Figure 1), both the bias correction and its standard deviation are obtained from curves fit to the data by the method of least squares. The bias curve is fit by a quartic and the standard deviation curve by a quadratic equation. For the gravimetric method (see Figure 2), the hias'correction is the average value over the
400 grams per liter range of the method; the standard deviation is the pooled standard deviation over the same range. Frror bars indicate the standard deviation of each hias. The two points withont error bars are the result of single measurements.

The solution volumes reported in Table II werte derived from tank-height readings made by Nuclear Safety personnel using Tank Calibration Certificates supplied by the Chemical Standards Laboratory. The tank-calibration program was initiated specifically to support this inventory; it was carried. out concurrently with the inventory. The calibration media were the uranium solutions in Forms 1 through 5 (instead of distilled water). This eliminated the waste-material recovery problem. A Standard Operating Procedure was established to assure reliable calibrations; several tanks were calibrated using solutions of various uranium concentrations to

\begin{tabular}{|c|c|c|c|c|}
\hline Form & $\begin{array}{c}\text { Concentration } \\
\text { (grams per liter) }\end{array}$ & $\begin{array}{l}\text { Volume } \\
\text { (liters) }\end{array}$ & $\begin{array}{c}\text { Uranium We } \\
\text { (grams) } \\
\end{array}$ & eight \\
\hline 1 & $483.6 \pm 4.0$ & $890.4 \pm 1.6$ & $430600 \pm 3$ & 643 \\
\hline 2 & $121.8 \pm 1.4$ & $231.8 \pm 0.6$ & $28232 \pm$ & 336 \\
\hline 3 & $115: 7 \pm 1.0$ & $612.6 \pm 1.0$ & $70875 \pm$ & 621 \\
\hline 4 & $80.6 \pm 0.8$ & $236.4 \pm 1.1$ & $19049 \pm$ & $20 \%$ \\
\hline 5 & $13.5 \pm 0.2$ & $481.9 \pm 1.1$ & $6503 \pm$ & 102 \\
\hline 6 & & & $510 \pm$ & 51 \\
\hline 7 & $22.2 \pm 0.2$ & $112.4 \pm 0.8$ & $2501 . \pm$ & 26 \\
\hline n and 9 & & & $3010 \pm$ & 150 \\
\hline
\end{tabular}

TABLE III. Enriched Uranium Isotopic Content as of January $31,1969$.

\begin{tabular}{cc} 
Uranium Is otope & Weight Percent \\
\cline { 2 - 2 } 235 & $93.19 \pm 0.04$ \\
238 & $5.37 \pm 0.04$ \\
234 & $1.015 \pm 0.010$ \\
236 & $0.43 \pm 0.01$ \\
233 & $<0.05$
\end{tabular}




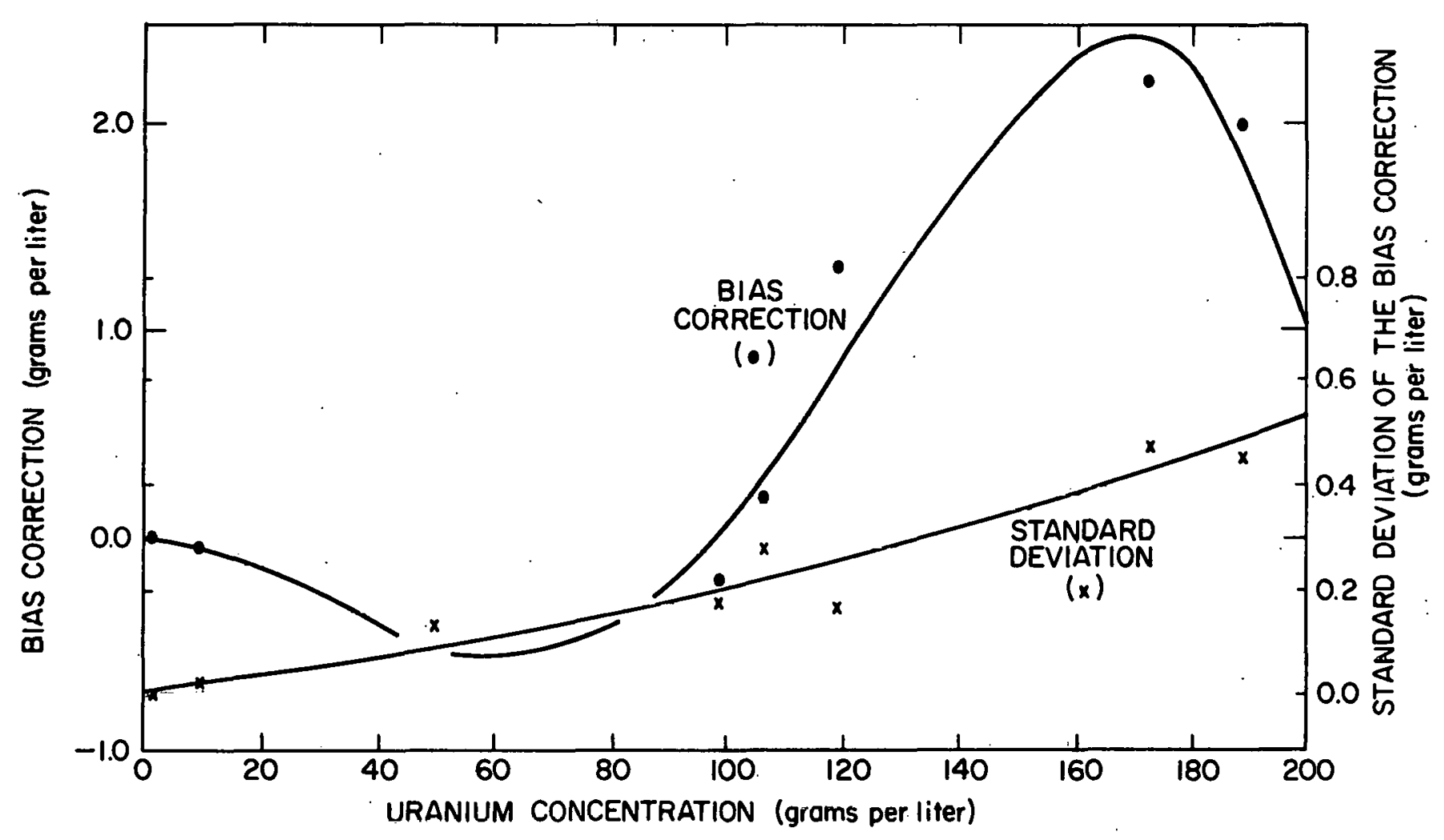

FIGURE 1. Analytical Laboratury Capability-Gamma Spectrometry Method.

FIGURE 2. Analytical Laboratory Capability, Gravimetric Method.

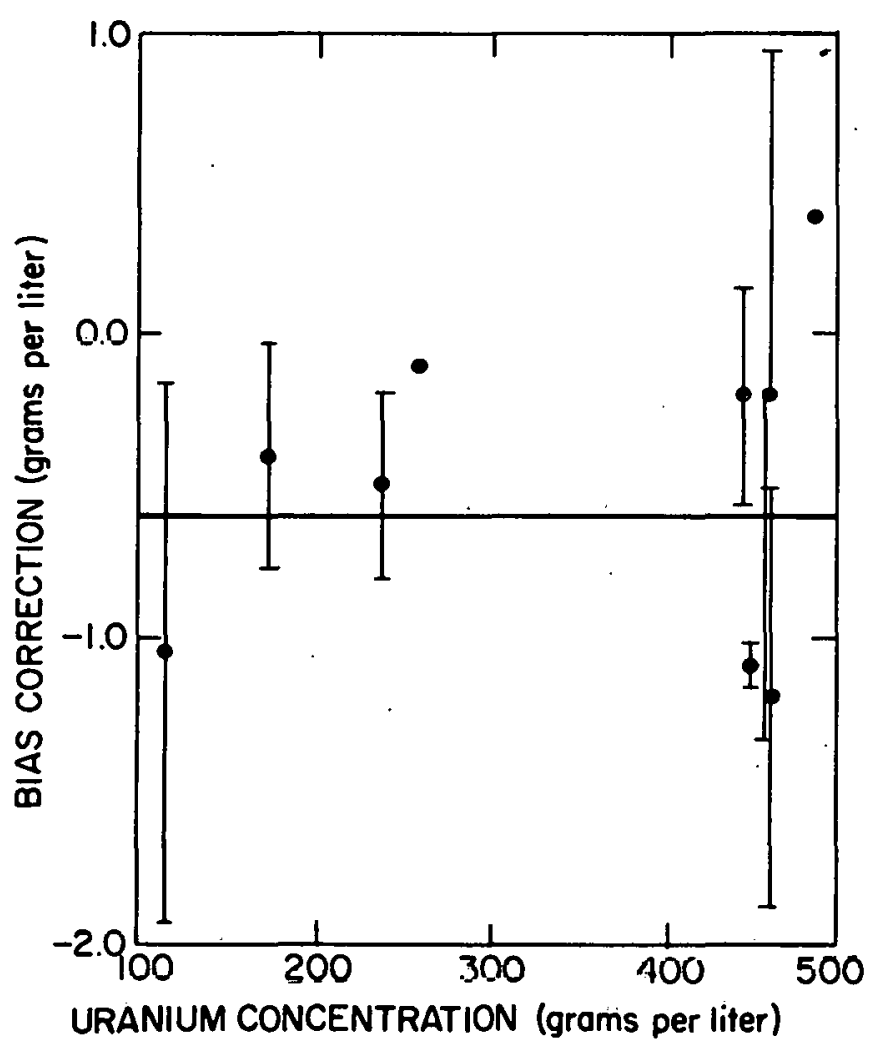

prove that the calibration was independent of the solution viscosity or density. This was proved, subject to some specific precautions. ${ }^{2}$

\section{DISCUSSION OF ERROR}

Measurement Uncertainties: The uncertainties presented in Table II evaluate statistical data only. They estimate the abilities of the various laboratories to measure solution heights, solution concentrations, and the bias of various Standard Operating Procedures. They assume some quantities to be precisely known: the linear standard for determining tank heights, the calibration standard volume, and the concentration of the standard solutions sent to the Analytical Laboratory.

The standard deviations of the volume determinations, calculated by Yvonne M. Ferris, reflect the following facts:

\footnotetext{
${ }^{1}$ L. W. Doher. Internal Private Communication. Chemical Standards Laboratory. December 1968.
} 
1. During the tank calibration, precisely known volume additions were made. This fact is assumed. Many volume-addition data points were obtained per tank.

2. At each data point, a single reading of the solution height was made by Chemical Standards Laboratory personnel.

3. At the time of the inventory volume determination, multiple readings of the tank height were made by several members of the Nuclear Safety Laboratory.

There exists a number of other sources of error which are not easy to estimate. The following paragraphs discuss these imponderable sources of error and offer crude estimates of their magnitudes in three cases.

Density Variations: A typical uranium solution storage tank contains more than 12,000 Raschig rings distributed vertically over 160 centimeters $(\mathrm{cm})$. Suppose such a tank, full of low concentration uranium solution $[\rho \approx 1.0$ grams per cubic centimeter $\left.\left(\mathrm{g} / \mathrm{cm}^{3}\right)\right]$, is drained until the effluence from the bottom of the tank is reduced to an occasional drop. This is the Chemical Standards Laboratory's definition of an empty tank. If then, concentrated uranium solution $\left(\rho \approx 1.67 \mathrm{~g} / \mathrm{cm}^{3}\right)$ is admitted to the top of the tank, it will wash down ahead of it the low density solution still clinging to the glass rings, such that a density difference will exist between materials in the tank and in the sight gauge. This effect could cause a gross error. For example, if the tank were filled with the high density material and the sight gauge contained low, the height in the sight gauge would be $107 \mathrm{~cm}$ greatcr than the height in the tank which corresponds to a 300 -liter error. This volume of 483.6 grams per liter solution contains 145,000 grams of uranium. To minimize this error, each tank is mixed for several hours taking care to flush the sight gauge. Several hours are required because experience indicates that highly concentrated uranium solution is difficult to homogenize.

The difference in densities of the liquid in the tank and the sight glass at the time of the inventory is difficult to estimate. Assuming a difference of $1 / 4$ percent. and that the tank is only half full (as was the case for the present inventory), then the error in the volume determination is 0.6 liters which, for high concentration solution, corresponds to about 250 grams of uranium. This estimate applies to one half-full tank only. For the inventory, three tanks contained concentrated solution, so the error in the uranium content would be more than 400 grams. Five other tanks contained lesser concentration solutions; their densities were correspondingly less (see Figure 3). They contribute to this error but to a lesser extent.

Some years ago, the volume of a tank as indicated by the sight gauge was in doubt. The liquid was Arained from the gauge and added to the top of the tank. When the solution was allowed to reenter the sight gauge, the new height differed by $10 \mathrm{~cm}$ from the old.

Thermal Expansion: If a Raschig ring-filled tank containing solution is allowed to warm up above the tank calibration temperature, the liquid and the rings will expand causing an overestimate of the volume, but the tank will expand tending to reduce the volume. The volume expansion coefficient for uranyl nitrate solution was measured by the Analytical Laboratory. They found a density change of $0.00067 \mathrm{~g} / \mathrm{cm}^{3}$ per ${ }^{\circ} \mathrm{C}$ for liquid having 400 grams of uranium per liter and 0.7 percent excess nitric acid. Table IV lists the expansion coefficients assumed and the corresponding changes in volume. The plus and minus signs state whether a temperature rise increases or decreases the indicated volume.

Temperature data ${ }^{2}$ collected from September 1968 through January 1969 from various locations within the solution storage room exhibit a range of $3{ }^{\circ} \mathrm{C}$ sugyesting that measured volumes might be in error by 0.12 percent because of differing temperatures. When this error is applied to each of the solution volumes in Forms 1 through 5 and Form 7 (see Table I), the corresponding error in the uranium determination is 700 grams.

Raschig Ring Holdup: When pumping solution into the top of a tank, the liquid wets the surface of each of the thousands of Raschig rings as it flows down to the rising liquid level in the tank. If the addition is stopped, the solution level in the tank will continue to rise as liquid drips from the rings. Figure 4 shows

\footnotetext{
${ }^{2}$ Temperatures in the room will be continuously monitored throughout the coming year in order to evaluate seasonal effects.
} 


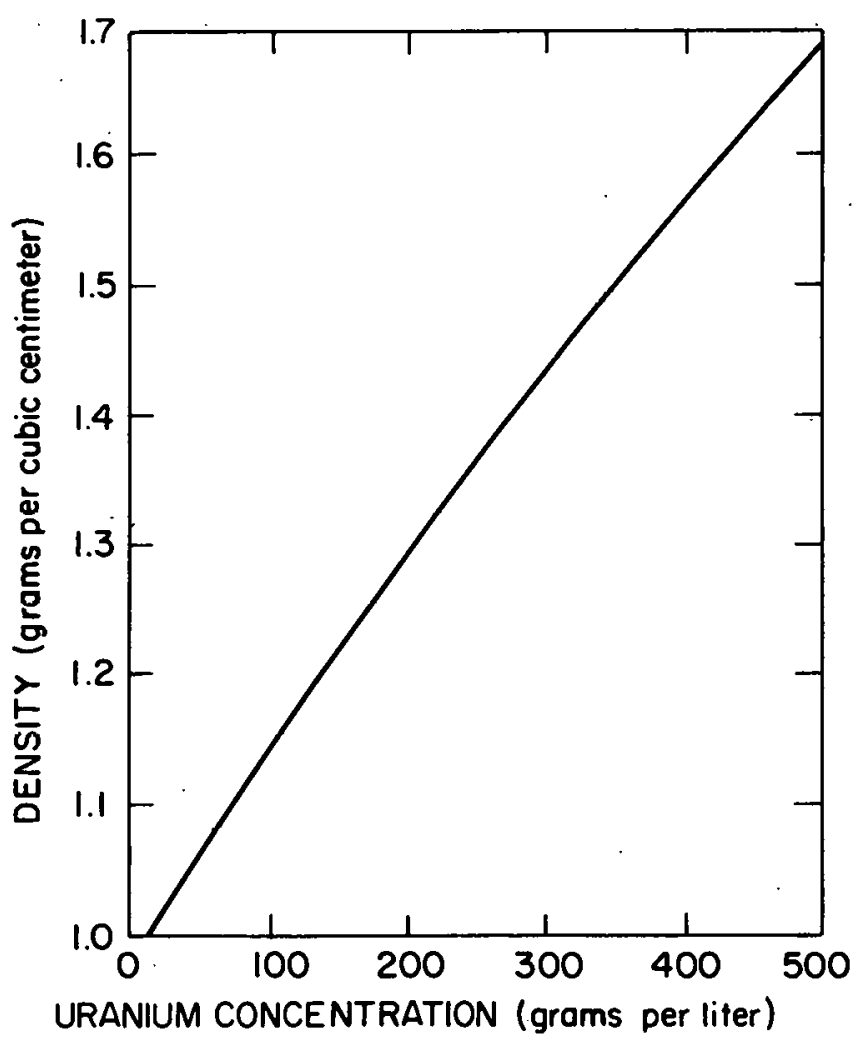

FIGURE 3. Density Variation of Uranyl Nitrate Solution.

TABLE IV. Volume Expansion Coefficients for Storage Tanks and Contents.

\begin{tabular}{lcc}
\multicolumn{1}{c}{ Material } & $\begin{array}{c}\text { Coefficient } \\
\left({ }^{\circ} \mathrm{C}^{-1}\right)\end{array}$ & $\begin{array}{c}\text { Percent Change in } \\
\text { Volume per }{ }^{\circ} \mathrm{C} \\
\text { (percent) }\end{array}$ \\
\cline { 2 - 3 } & $\begin{array}{l}430 \times 10^{-6} \\
\text { Solution }\end{array}$ & +0.043 \\
Raschig Rings & $25 \times 10^{-6}$ & +0.003 \\
Storage Tank & $36 \times 10^{-6}$ & -0.004 \\
Net Change in Indicated Volume Per ${ }^{\circ} \mathrm{C}$ & - & +0.042 \\
\hline
\end{tabular}

the increase in volume with time following the termination of liquid addition to the tank. For this measurement, rings were wet above the liquid level to a height of $130 \mathrm{~cm}$. If only half that height of rings had been wet, half the solution increase after any elapsed time, would have been expected. The arrow in Figure 1 at two minutes shows the time waited by the tank calibration people following each volume addition before reading. It was not possible for each of the Nuclear Safety readers to take all the ir measurements at the two-minute mark. In practice, the volume determinations were made from 30 scconds to 30 hours after pumped additions to the tank had been stopped. Assuming that range in time, Figure 4 suggests that volume determinations were within \pm 1 liter of the value which existed after the standard calibration waiting period of two minutes. Adjusting this uncertainty for the various heights of wet rings over the liquid in each tank and converting that volume error to a uranium error yields an estimated error in the uranium inventory of about \pm 900 grams.

Aeration: The homogenization of uranium solution requires many hours of vigorous mixing. The nominal flow rate of the mixing pump is one liter per second. This motion can dissolve air bubbles in the uranium solution which displaces solution within the tank, yielding an overestimate of the true solution volume. No evaluation of this effect is given.

Past experiences do show that bubbles are formed by vigorous pumping. For example, a small pump is connected to the lowest point in the solution storage room piping. The pump connects to a small-diameter, clear-plastic tube rising vertically to a header above the level of the storage tanks. The system is used to drain the pipes of all solution, during invent ory operations for example. Whenever air mixes with the liquid in this pump, the effluent, visible in the clear

FIGURE 4. Increase in Solution Height as Solution Drips from Raschig Rings.

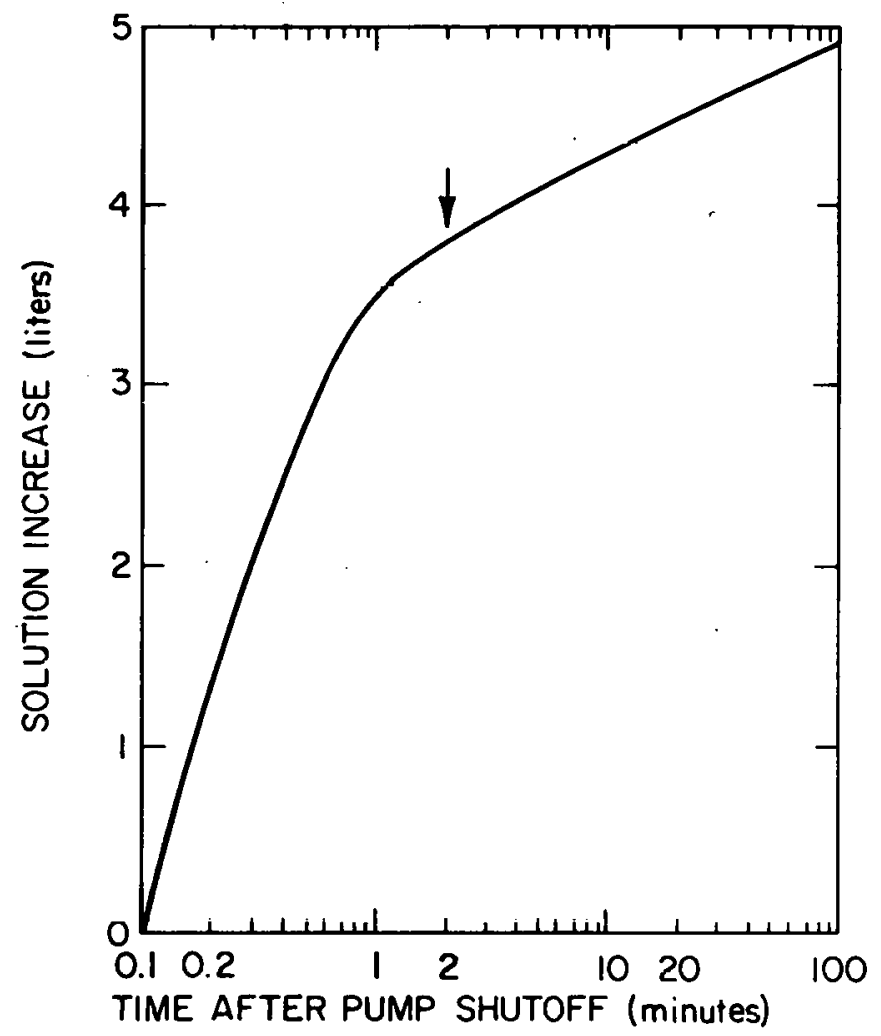


tubing, changes from a clear yellow liquid to an opaque yellow foam. The clarity returns to the solution within a few seconds following pump shutdown, but no estimate is made for the aeration of the liquid or its accompanying change in volume. A second example comes from experiments done in the Nuclear Safety Laboratory. Solution additions to an experimental system up to a multiplication of about 2 are frequently made using the one-liter per second pump. If the apparatus design permits, this reactivity addition is viewed on closed-circuit television. Bubbles of assorted sizes and foam are always seen. Nearer criticality slower pumps are used and bubble formation essentially vanishes. A final example pertains to the uranium solution leak to the hot exhaust system which was discovered November 30,1967 . Uranium solution rose in the scram-tank vent line approximately one meter above the level the liquid had in the experimental apparatus before the scram was initiated. Investigation showed that many bubbles over a wide range of sizes were formed during the scram. These bubbles displaced the uranium solution upward allowing some to reach the hot exhaust system.

Sampling Error: This final imponderable error is also difficult to assess. The total volume of uraniumcontaining solution at the time of the present inventory was about 2,500 liters. Only four liters of this was actually analyzed to determine the six concentrations reported in Table II. This sampling $(0.16$ percent) is small, when attempting to accomplish an inventory with a precision better than one percent. Although procedures are followed which minimize the following sources of error, they certainly exist but to an unknown extent. A sample collected to represent solution of one concentration may push ahead of it (into the sample vial) nonre presentative solution remaining since the last sample withdrawal. The solution sample may dislodge a salt crystal from the sample port. This crystal will dissolve in the solution leading to an overestimate of the concentration of that sample. Once collected, the sample is not always analyzed within a few hours. The delay occasionally lasts a week. During that time, the solution might lose or pick up water from the atmosphere even though capped. The high concentration solution might begin to salt out because of a small amount of dirt or impurities in the sample vial. Finally, the uranium solution concentration is analyzed at $23.0^{\circ} \mathrm{C}$. The temperature of the solution storage room is known to vary a few degrees about that temperature; consequently, the solution concentration determined by the Analytical Laboratory is likely to be slightly different than the concentration which was in the tank at a slightly different temperature.

Discussion: Other imponderable errors probably contribute to differences between inventories which have been overlooked by Nuclear Safety personnel. Each of the five imponderable errors discussed probably contribute from many hundreds of grams to one or two kilograms error in the uranium solution inventory. This error, plus the \pm 4 -kilogram measurement uncertainty derived by Yvonne M. Ferris, sum to an expected descrepancy between successive inventories which might well exceed 5 kilograms, but will probably be less than 10 kilograms. Nevertheless, the measurement uncertnintics, when calculated by people with different background abilities for statistical analysis (the auth or has had no statistical training), appear to range between \pm 3 and \pm 4 kilograms.

In the $3 \frac{1}{2}$ years that uranium solution has been in use at the Nuclear Safety Laboratory, four high precision inventories have been performed. The differences between each and the preceding one adjusted for measured additions and removals (small compared to the total inventory) have been $322 ; 6,114$; and 644 grams; respectively.

\section{CONCLUSIONS}

Accurate data relative to the measurement of enriched uranium inventories have been somewhat limited in the past because the large through-put of a processing plant makes such accuracy difficult. The closed facilitics at the Rocky Flats Nuclcar Safety Facility and the current research assignments have provided a unique advantage in conducting measurement experiments which could be of use to other industries involved in similar work. Furthermore, the problems discuvered and solved at Rocky Flats Plant can help others avoid them and may suggest other difficulties not included in this discussion.

It is hoped that the methods presented and the problems discussed will help others formulate a reliable procedure for the inventory of valuable materials, such as uranium and plutonium. In addition, it is hoped that this report will contribute to a savings of time and effort and to an increase in the time the material is available for experimental purposes, when establishing similar programs elsewhere in the nuclear energy field. 


\title{
APPENDIX A. LIMIT OF ERROR APPLICABLE TO THE ENRICHED URANIUM INVENTORY
}

\author{
Yvonne M. Ferris
}

\author{
Scientific Systems \\ Management Systems \\ nocky Flats Division
}

The total uranium weight, as determined by the physical inventory of November 1968 is 561,280 grams. The limit of error (LE) is 3,721 grams. Table I-A lists the statistics from which these quantities were calculated; the limit or error is twice the standard deviation.

\section{Volume:}

Personnel from the Chemistry Standards Laboratory calibrated each tank by adding known-volume increments to the tank and comparing the liquid level in the sight gauge with a linear standard after each increment. From these data, the slope and intercept of a straight line were calculated. The volume for the physical inventory was calculated from the leastsquares equation using the sight gauge reading as determined by Nuclear Safety and the appropriate intercept and slope from the Chemistry Standards Laboratory volume-calibration certificate. ${ }^{A-1} \mathrm{~A}$ description of the method for calculating the standard deviation of the volume may be found in the work by Mandel. A-2

\section{Concentration:}

The concentration is the mean of multiple samples each having two analytical results. The standard

\footnotetext{
${ }^{A-1}$ Incernal Technical Procedure No. 504; and L. W. Doher and J. I.. Srihulz. Volume Calibration of Process Vessels by Digital Computer Techniques. RFP-488. Rocky Flats Division, The Dnw Chemical Company, Golden, Colorado. 1966.

A-2 John Mandel. The Statistical Analysis of Experimental Data. Interscience Publishers, New York. 1964. Pages 272-294.
}

deviation of the concentration is a combination of the pooled standard deviation within each sample and the standard deviation between samples.

Bias, Gamma Spectrometry Method:

The bias of concentrations determined by the gamma spectrometry method was computed by fitting a quartic equation to 8 biases calculated at concentration levels ranging from 1.05 to 189.1 grams per liter.

Bias is defined as the mean of differences between a standard value certified by Chemistry Standards Laboratory and an observed value representing a chemical analysis. The differences are calculated by subtracting the standard value from the observed value. A negative bias, therefore, illustrates a consistent tendency for the analytical results to be less than the true concentration in the sample.

The quartic equation obtained by the method of least squares and used to calculate the biases shown in Table I-A is:

$$
\begin{gathered}
y=-0.0076965+0.00534722 x-7.228396 \times 10^{-4} x^{2} \\
+1.00102 \times 10^{-5} x^{3}-3.18654 \times 10^{-8} x^{4} \\
y-\text { calculated bias in grams per liter } \\
x-\text { concentration level in grams per liter }
\end{gathered}
$$

The coefficients of Equation No. 1-A were computed by weighting each of the 8 biases with the reciprocal of the standard deviation of the differences at each 
TABLE I-A. Enriched Uranium Inventory and the Statistics from which Calculated.

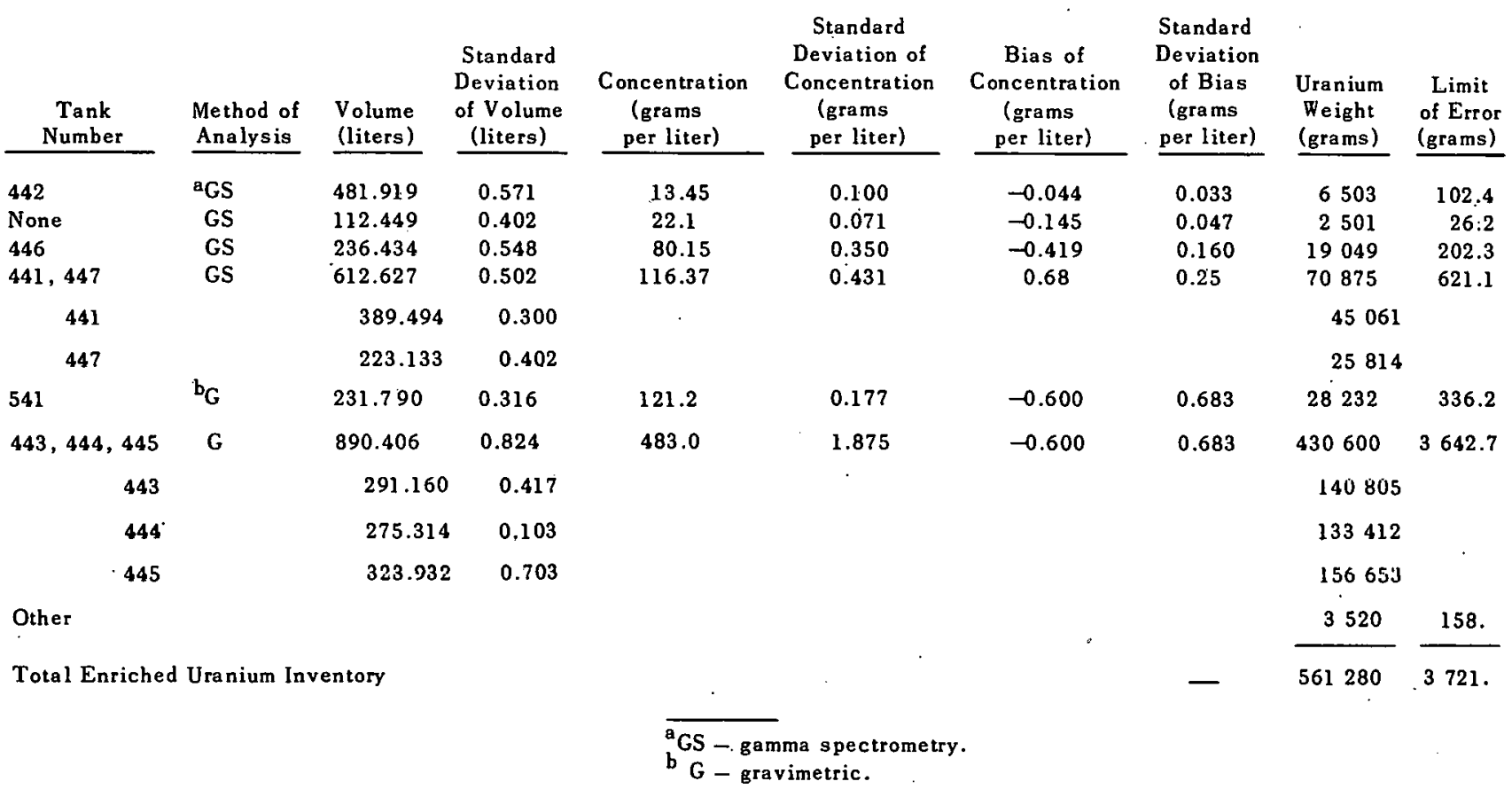

concentration level. ${ }^{\text {A-3 }}$ The standard deviations used as weighting factors were calculated from a least squares determined quadratic equation:

$$
\begin{aligned}
& y=0.014618+1.30261 \times 10^{-3} x+6.38837 \times 10^{-6} x^{2} \\
& y \text { - calculated standard deviation in } \\
& \text { grams per liter } \\
& x \text { - concentration level in grams per liter }
\end{aligned}
$$

The standard deviation of concentration appearing in Table I-A was obtained from the solution of Equation No. 2-A for each of the four concentration levels determined by gamma spectrometry.

\section{Bias, Gravimetric Method:}

The bias and standard deviation of the differences from which the bias is calculated displayed no functional trends when plotted against levels of

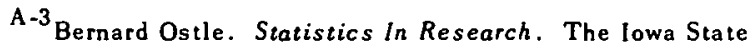
University Press, Ames, lowa. 1963. Page 197.
}

concentration as determined by the gravimetric method. The bias, therefore, is the mean of all the differences. The standard deviation was computed by pooling the standard deviation at each level of concentration.

Limit of Error:

The errors were propagated according to standard statistical practices as discussed by Beers. ${ }^{A-4}$ The limit of error is twice the propagated standard deviation. Concentrations were corrected for bias. All other errors were assumed to be completely random. This assumption is probably incorrect and would tend to understate slightly the total error. There is no available estimate of the correlation between the standard deviation and therefore, greater detriment would result from presuming the true relationship than in assuming randomness.

\footnotetext{
${ }^{A-4}$ Yardley Beers. Introduction to the Theory of Error. Addison and Wesley Publishing Company, Inc., Reading, Massachusetts. 1957.
} 